\title{
Dissolution enhancement and physicochemical characterization of fenofibric acid in surface solid dispersion with croscarmellose sodium
}

\author{
Yulias Ninik WINDRIYATI 1, 2 * D , Yeyet Cahyati SUMIRTAPURA ${ }^{1}$ (D), Jessie Sofia PAMUDJI ${ }^{1}$ (iD \\ 1 School of Pharmacy, Bandung Institute of Technology, Ganesha 10, Bandung 40132, Indonesia. \\ 2 Faculty of Pharmacy,Wahid Hasyim University, Menoreh Tengah X, Semarang 50236, Indonesia. \\ * Corresponding Author. E-mail: yninik@unwahas.ac.id (Y.N.W); Tel. +62-24-8505680.
}

Received: 05 September 2018 / Revised: 18 October 2018 / Accepted: 31 October 2018

\begin{abstract}
The dissolution enhancement of the water-insoluble drug fenofibric acid (FA) was conducted by the surface solid dispersion (SSD) technique with croscarmellose sodium (CS) as a carrier. The SSD formulations of FA were prepared by the solvent evaporation method in three different drug-to-carrier weight ratios, evaluated for the dissolutions, and compared to the physical mixtures (PMs). The optimum SSD formulation and its corresponding PM were characterized by Scanning Electron Microscopy (SEM), Powder X-ray Diffraction (PXRD), Differential Thermal Analysis (DTA), and Fourier Transform Infrared Spectroscopy (FTIR) and were compressed into tablets to evaluate the dissolution after compression. The best dissolution was obtained from the SSD 1:1. The recrystallization of FA in the SSD preparation could change the crystal habit of FA and deposited it on the surface of CS. In addition, there was no chemical interaction observable between both FA and CS in the SSD formulation. No chemical interaction between FA and CS in the SSD. However, a slight reduction was noticed in the crystallinity of FA if compared to that of the pure drug. This study showed that the SSD formulation had the best dissolution compared to the PM, the conventional direct compression, and the reference formulation of FA in its commercial tablets. The SSD preparation with CS could enhance the dissolution of FA from its tablet dosage form.
\end{abstract}

KEYWORDS: Fenofibric acid; surface solid dispersion; croscarmellose sodium; dissolution; physicochemical characterization.

\section{INTRODUCTION}

Fenofibric acid (FA), the active moiety of fenofibrate (fibrates group), is an antihyperlipidemic agent because it is a synthetic ligand that binds to nuclear peroxisome proliferator-activated receptors alpha (PPARa) [1-3]. FA has been used as a single drug or combined with other drugs in the treatment of hyperlipidemia [4-6]. A carboxylic acid moiety, FA comes with the chemical name of (2-[4-(4-chloro benzoyl) phenoxy]-2-methyl propanoic acid). It is an almost white, odorless, tasteless compound with molecular weight 318.75 and molecular formula $\mathrm{C}_{17} \mathrm{H}_{15} \mathrm{ClO}_{4}$. Obtained from ethanol solution, a single crystal of $\mathrm{FA}$ is a platelike and orthorhombic crystal [7]. FA is well absorbed through the gastrointestinal tract [8], but it has relatively poor solubility at gastric $\mathrm{pH}$ and fairly good solubility at intestinal $\mathrm{pH}$ [1]. Due to its adequate permeability, FA is classified as a class II drug in the Biopharmaceutical Classification System (BCS). The poor solubility of FA in water may cause its dissolution to be reasonably slow and its bioavailability to be unpredictable.

Approaches to enhance the dissolution and bioavailability of FA have not been widely reported. There is only one approach reported to use in order to enhance the solubility, dissolution, and oral bioavailability of FA; that is by adding alkalizing solubilizer $[9,10]$. The commercial formulations of Fibricor ${ }^{\circledR}$ and its generic version Fenofibric acid ${ }^{\circledR}$ weigh $840 \mathrm{mg}$ and consist of a large number of ingredients for the active substance of $105 \mathrm{mg}$. And a new formulation of FA with enhanced dissolution and fewer ingredients was developed in this study.

The dissolution of BCS class II drugs is the limiting step for their oral bioavailability. The solid dispersion technique has often proved to be successful in enhancing the dissolution of poorly soluble drugs by reducing the drug particle size, improving the drug wettability, and presenting the amorphous state [1113]. Still, this technique has limitation to be applied to such drugs due to their poor physical characteristics for

How to cite this article: Windriyati YN, Sumirtapura YC, Pamudji JS. Dissolution enhancement and physicochemical characterization of fenofibric acid in surface solid dispersion with croscarmellose sodium. J Res Pharm. 2019; 23 (2): 315-325. 
dosage form development and their difficulty for being handled in the tablet preparation $[14,15]$. Surface solid dispersion (SSD) is a technique developed to enhance the dissolutions of active substances. Unlike in the conventional solid dispersion, the carriers used in this technique are typically water-insoluble, porous, and naturally hydrophilic. The recrystallization and deposition of drug particles in the SSD preparation leads to a reduction in the agglomeration and particle size of the drug so that it not only increases the surface area but also provides an even faster dissolution $[16,17]$. In relation to SSD, the solvent evaporation method can be done by a simple way. The dried mass obtained from the SSD formulation is easier to pulverize than from the conventional solid dispersion formulation [15].

Various carriers commonly utilized as tablet excipients such as microcrystalline cellulose, crospovidone, croscarmellose sodium (CS), sodium starch glycolate, and silicon dioxide have been of use for the SSD preparation. The preliminary investigation of selected carriers showed that only CS could enhance the dissolution of FA significantly. Frequently used as a disintegrant in the tablet preparation, CS itself is a crosslinked polymer of sodium carboxymethylcellulose. It has an ability to disintegrate tablets more rapidly into particles than sodium starch glycolate and crospovidone [18]. The main objective of this study was to develop a novel oral pharmaceutical formulation of FA, using the SSD formation with CS as an adsorbent carrier by the solvent evaporation technique. Additionaly, this study also focused on evaluations of the CS influence on the dissolution of FA, the physicochemical characterization of the optimum SSD, and the compression force influence on the dissolution of FA from the SSD tablets.

\section{RESULTS AND DISCUSSION}

\subsection{SSD Formation}

All SSDs were found to be fine and free flowing powders. They were prepared by the solvent evaporation method using ethanol. This solvent was chosen because of the high solubility of FA in ethanol, and the crystal obtained from the ethanol solution was included in thermodynamically stable Form II [7, 19]. In the SSD preparation, the agitation provided by a rotary evaporator had to be sufficient in order to prevent the settling of insoluble CS particles. Insufficient agitation tended to cause non-uniformity in the distribution of drug on the carrier surface [20].

\subsection{Drug Content}

UV spectroscopy assay was employed to confirm the homogeneity of FA on the carrier CS. The spectrophotometry method validated for linearity, accuracy, precision, and interference. The CS did not interfere in this method. The calibration curve showed linearity in the concentration range of $4-14 \mu \mathrm{g} / \mathrm{ml}$. The regression coefficient $\left(\mathrm{R}^{2}\right)$ value found to be 0.998 and the slope value was 0.058 . The actual drug contents in all the prepared SSDs and PMs were of 96-101\% from theoretical value $105 \mathrm{mg}$ (Table 1). These results signified both the absence of drug loss in the preparation and the uniformity of the drug content in each batch prepared $[21,22]$. Accordingly, the method used in this study seemed to be reproducible.

\subsection{Dissolution Evaluation}

The dissolutions of FA obtained from the prepared SSDs, PMs, and pure drug were determined in this study. $\mathrm{DE}_{60}$ values were used to characterize the dissolution efficiencies (in $60 \mathrm{~min}$ ) of drugs dissolved from dosage forms. The complete values are given in Table 1. Due to its insolubility in water, the pure drug of FA exhibited the tendency to form large aggregates and to flow on the surface of the dissolution medium. The aggregation produced a reduction in the effective surface area of particle available for wetting and dissolution into $40 \%$ of $\mathrm{DE}_{60}$. The dissolution enhancement of FA from the recrystallized FA (62\% of $\left.\mathrm{DE}_{60}\right)$ revealed that the recrystallization process from the ethanol solution changed the crystal properties of FA, one of which is its crystal habit. The $\mathrm{DE}_{60}$ values of PMs were higher than that of the pure drug, following the presence of the carrier CS in the respective mixtures. The improvement of the $\mathrm{DE}_{60}$ values from PMs was comparable with that of the recrystallized FA. The presence of CS and the change of its crystal habit yielded significant improvement in the dissolution. The SSD formulation with ratio 1:1 (SDCS11) had the highest $\mathrm{DE}_{60}$ value among all formulations. The enhancement of the CS concentration in the SSD formulation in a ratio of 1:2 (SDCS12) could not improve the extent of drug dissolved. In most cases, an increase in the carrier content could improve the dissolution profile of drug [20]. Yet this method was unable to be implemented in this study as a consequence of a large amount of the SDCS12 material left in the basket during the dissolution testing. Actually, the SSD was able to improve the dissolution better than its corresponding PM if CS was added and the crystal habit of FA was shifted. Besides, its deposition on the carrier's surface was also able to improve the 
wetting of the FA particles when it contacted the medium. The high swelling and hydration capacities of the CS particles would lead to the cluster deaggregation of the FA particles and facilitate the dissolution process $[20,24]$. This is associated with their water-efficient properties when they are in contact with the medium.

Table 1. The composition of surface solid dispersions and physical mixtures of fenofibric acid, drug content, and $\mathrm{DE}_{60}$.

\begin{tabular}{|c|c|c|c|c|}
\hline Code & Method & $\begin{array}{l}\text { Ratio } \\
\text { drug: } \\
\text { carrier }\end{array}$ & $\begin{array}{c}\text { Ratio between actual \& } \\
\text { theoretical content of drug } \\
\text { in the sample }(\%)\end{array}$ & $\mathrm{DE}_{60}(\%)^{*}$ \\
\hline SDCS21 & Surface solid dispersion & $2: 1$ & $101.73 \pm 3.70$ & $65.25 \pm 3.84$ \\
\hline SDCS11 & Surface solid dispersion & $1: 1$ & $100.62 \pm 3.06$ & $82.43 \pm 3.59$ \\
\hline SDCS12 & Surface solid dispersion & $1: 2$ & $96.57 \pm 4.39$ & $74.19 \pm 5.99$ \\
\hline PMCS21 & Physical mixture & $2: 1$ & $98.59 \pm 3.78$ & $66.26 \pm 4.39$ \\
\hline PMCS11 & Physical mixture & $1: 1$ & $99.34 \pm 2.99$ & $67.70 \pm 3.73$ \\
\hline PMCS12 & Physical mixture & $1: 2$ & $101.05 \pm 4.38$ & $66.76 \pm 4.61$ \\
\hline pure FA & - & - & $99.38 \pm 1.85$ & $40.34 \pm 2.22$ \\
\hline Recryst FA & recrystallization & - & $99.08 \pm 1.51$ & $62.33 \pm 3.04$ \\
\hline
\end{tabular}

\subsection{Physicochemical Characterization}

\subsubsection{Scanning electron microscopy (SEM)}

The microphotographs of the pure FA, the recrystallized FA, SDCS11, and its corresponding PM (PMCS11) are shown in Figure 1. The particles of the pure FA, agglomerates of cubic-like crystals, turned into plates after recrystallization in ethanol [7]. While the rod-shaped CS particles in the PMCS11 existed as individual particles with FA dispersed in the native crystalline form [24]. Comparatively, FA in the SDCS11 was present in form of fine particles on the CS surface, meaning it lost the original shape.

The plate-shaped crystal of FA exhibited a significantly faster dissolution owing to the higher specific surface area they had than that of the originally shaped one. Different crystal forms largely influenced the wettability and subsequent dissolution of drug. Based on the microscopic photographs, it could be stated that the FA particles underwent changes in crystal habit in the recrystallization process during the SSD formation and occupied the surfaces of the CS particles. Different crystal habits between the starting material and the recrystallized FA made an alteration to the FA dissolution.

\subsubsection{Powder X-ray diffraction (P-XRD)}

XRD was used to trace any changes present in the crystalline state of FA and to determine the possibility of polymorphic changes of drug in the SSD formulation that may affect its dissolution. Figure 2 illustrates the $\mathrm{X}$-ray diffractions of the samples. The diffractogram indicates that the pure FA is crystalline as demonstrated by specific peaks at the diffraction angles $(2 \theta)$ of $18^{\circ}, 19^{\circ}, 21^{\circ}$, and $23^{\circ}[9]$ with crystallinity value $86.69 \%$. According to the XRD pattern, the recrystallized FA had more diverse peak intensities than the pure FA, and

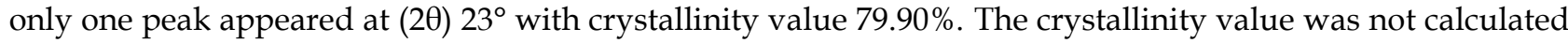
manually, but obtained automatically from the instrument. Different diffractograms between both samples were mainly caused by different crystal habits. In this regard, the pure FA, serving as the starting material, was cubic-shaped, while the recrystallized FA was plate-shaped.

The presence of a peek at $(2 \theta) 23^{\circ}$ showed no decrease in intensity in either SDCS11or PMCS11, but a slight reduction in crystallinity of each from $79.90 \%$ to $52.42 \%$ and from $86.69 \%$ to $59.54 \%$ respectively. In addition, there were no new peaks observed in the XRD patterns of both SDCS11 and PMCS11. Thus, the possibility of any conversion into polymorphic form could be disregarded [23]. The reduction of crystallinity in SDCS11 was not significantly different from that in PMCS11 due to the dilution effect of CS [25]. Based on the XRD analysis, the processes of the SSD and PM formulations resulted in a decrease in the FA crystallinity. 

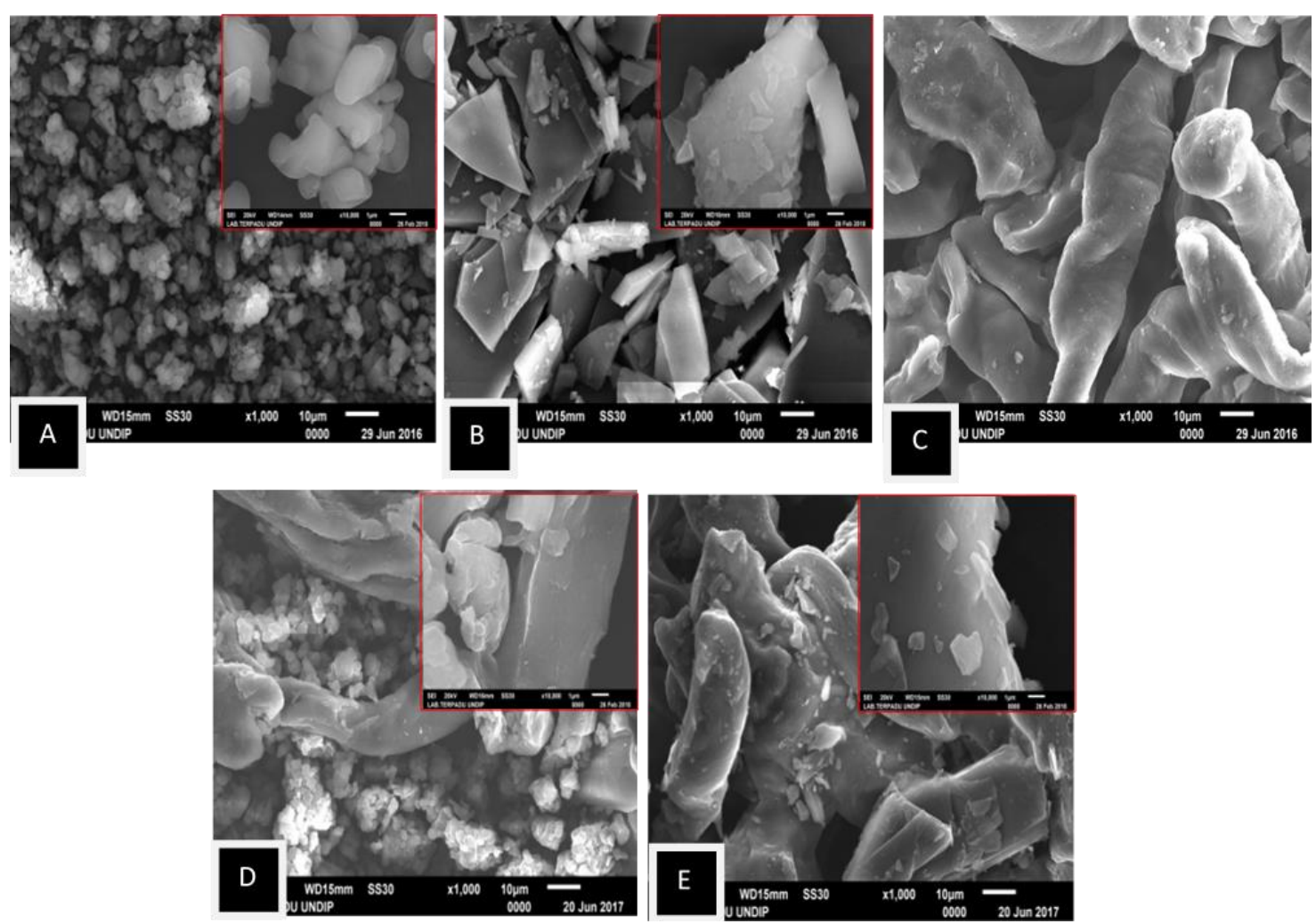

Figure 1. SEM images at magnification 1000x of (A) pure FA, (B) recrystallized of pure FA, (C) croscarmellose sodium, (D) the physical mixture PMCS11, and (E) the surface solid dispersion SDCS11. Insert indicated the magnified image at 10,000x.

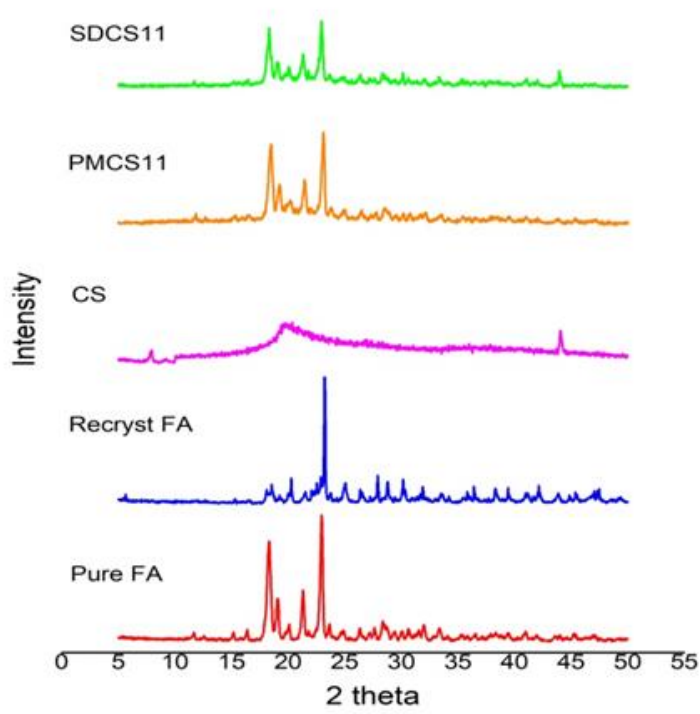

Figure 2. XRD diffractograms of pure FA, recrystallized of pure FA, croscarmellose sodium, the physical mixture PMCS11, and the surface solid dispersion SDCS11. 


\subsubsection{Differential thermal analysis (DTA)}

DTA was used to determine any physicochemical interaction between FA and CS. The DTA curve of the pure FA (Figure 3) exhibited a sharp endothermic peak at $184.97^{\circ} \mathrm{C}$, serving as the melting point of FA (Form II) [19]. CS did not indicate an endothermic fusion as shown by the crystalline materials, which means CS is naturally amorphous. The characteristics of the endothermic peaks of FA in both PMCS11 and SDCS11 still showed the same temperatures $\left(184.38\right.$ and $\left.184.03^{\circ} \mathrm{C}\right)$. A decrease, however, occured in sharpness and intensity of the characteristic endothermic peak of drug, which was possibly caused by the conversion of fraction of crystalline form into amorphous form.

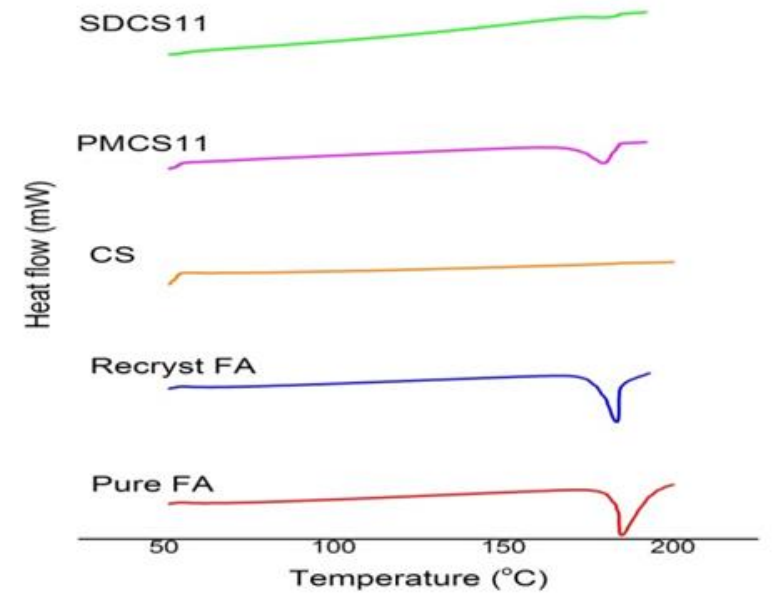

Figure 3. DTA patterns of pure FA, recrystallized of pure FA, croscarmellose sodium (CS), the physical mixture PMCS11, and the surface solid dispersion SDCS11.

Based on the US patents, there have been two well-known polymorphs of FA. The first form (Form I) melts at temperatures $175-176{ }^{\circ} \mathrm{C}$, while the latter (Form II) does at $184-185{ }^{\circ} \mathrm{C}$ and seems to be more thermodynamically stable at elevated temperature (above $45^{\circ} \mathrm{C}$ ) [19]. Difference in the thermodynamic state as well as other properties of various polymorphs influences the dissolution behavior and stability of formulation during manufacturing or storage. A metastable form can easily transform into a thermodynamically stable form. It is crucial to select the most stable polymorph for the product development. Generally, the stable polymorph chosen should be thermodynamically stable during the manufacturing process. And this study signified that there was no change in the melting point of FA, meaning the drug was in a stable form and the crystallinity of FA was persistent, despite the presence of amorphous forms in both formulations of SDCS11 and PMCS11 [22, 26].

\subsubsection{Fourier transform infrared (FTIR) spectroscopy}

FTIR spectroscopy was used to examine any structural changes as well as any possible interaction between FA and CS in the SSD formulation. The FTIR spectrums of SDCS11, PMCS11, and the pure FA are presented in Figure 4. The IR spectrum of the pure FA showed a characteristic broadband at wave number $2991 \mathrm{~cm}^{-1}$ (O-H stretch), indicating that carboxylic acid existed in the dimer structure. The bands at $1708 \mathrm{~cm}^{-1}$ ( $\mathrm{C}=\mathrm{O}$ stretch) and $1647 \mathrm{~cm}^{-1}(\mathrm{C}-\mathrm{C}=\mathrm{C}$ symmetric stretch) showed the functional groups of alkene and ketone. The bands at $1593 \mathrm{~cm}^{-1}$ and $1498 \mathrm{~cm}^{-1}(\mathrm{C}-\mathrm{C}=\mathrm{C}$ symmetric stretch) indicated aromatic rings, and the vibrations on $759 \mathrm{~cm}^{-1}$ and $671 \mathrm{~cm}^{-1}$ signaled the existence of alkyl halide $(\mathrm{C}-\mathrm{Cl})$.

The IR spectrums of SDCS11 and PMCS11 showed no substantial shifting in the positions of the functional groups. No bands shifted, broadened, or even missed at the FTIR spectrum of both SDCS11 and PMCS11. Also, no new bands appeared and no chemical bond occurred in those spectrum, signaling that there was no chemical interaction formed between both FA and CS [21,24]. 


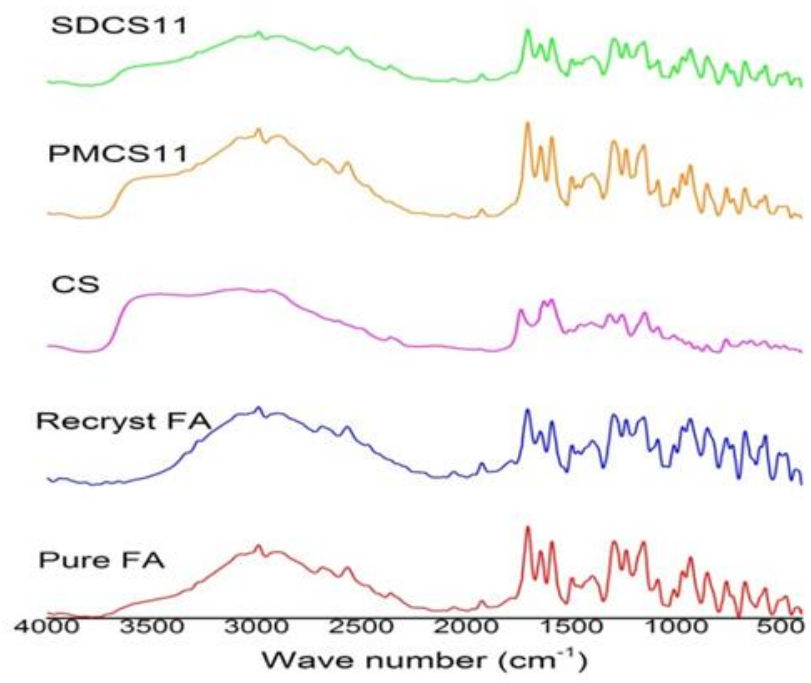

Figure 4. FTIR spectrums of pure FA, recrystallized of pure FA, croscarmellose sodium, the physical mixture PMCS11, and the surface solid dispersion SDCS11.

\subsection{Characteristic of FATablet}

SDCS11, containing $105 \mathrm{mg}$ of the drug (F1), was compressed into tablet using the direct compression method. PMCS11 (F2) and the conventional formulation (F3) were also prepared per formula for comparison as given in Table 2. Avicel PH 101 and Magnesium stearate were added to each formula as a diluent and lubricant in order to increase the flowability of each powder blend that should have measured more than 4 $\mathrm{g} / \mathrm{sec}$. It was found that the flowabilities of the powder blends of F1, F2, and F3 were 7.73, 3.93, and 2.14 g/sec respectively. The powder blends of F2 and F3 had relatively poor flowability, so the tablets were compressed manually. Although the pre-compression powders of F2 and F3 did not fulfill the requirement, the objective of this experiment was to observe the influence of compression force on the dissolution of FA from the SSD tablet. Therefore, no additional excipient was used in the formula.

All prepared tablets satisfied the requirements (data not shown). For tablets weighing less than $400 \mathrm{mg}$, the hardness should have been $4-6 \mathrm{~kg} / \mathrm{cm} 2$, and the friability should have been less than $1 \%$. The hardness and friability of all prepared tablets met the requirements, suggesting that Avicel PH 101 was used not only as a diluent but also as a binder in the tablet formula. The disintegration times of all prepared tablets were less than 1 minute. Avicel PH 101 and superdisintegrant CS facilitated the water to enter the tablet pores. The uniformity of the weight and content of FA in all prepared tablets satisfied the requirements, signifying that there was no trouble in the tablet preparation process.

The dissolution profiles of all prepared tablets compared to those of the reference tablet $\left(\mathrm{FA}^{\circledR}\right)$ are shown in Figure 5. The drug dissolved from F1 was larger than from F2, F3, and FA ${ }^{\circledR}$. The DE 60 of F1 (93.74 $\left.\pm 4.39 \%\right)$ was markedly different from those of F2 (83.74 $\pm 1.40 \%)$, F3 (78.40 $\pm 1.05 \%)$, and FA ${ }^{\circledR}(74.27 \pm 1.56 \%)$. Based on the statistical analysis conducted using one-way ANOVA $(\mathrm{p}<0.05)$ and Post Hoc Test, the DE 60 differences among all tablets were reasonably significant, except those between F3 and FA ${ }^{\circledR}$. F1 and F2 were able to reach the dissolution efficiency for more than $80 \%$ in $60 \mathrm{~min}$ attributed to the amount of CS component (105 $\mathrm{mg}$ /tablet) that facilitated the dissolution process of FA in the medium. On the other hand, F3 was unable to reach the same $\mathrm{DE}_{60}$ as $\mathrm{F} 1$ and F2, considering the fact that the content only weighed $15 \mathrm{mg}$ of CS (around $5 \%$ /tablet), which was used as a disintegrant. In relation to $\mathrm{DE}_{60}$, all prepared tablets (weighing $300 \mathrm{mg}$ ) were comparable to the reference $\mathrm{FA}^{\circledR}$ (weighing $840 \mathrm{mg}$ ). The compression process did not give any influence on the dissolution of FA from both SSD and PM [15]. 
Table 2. The composition of three formulations of fenofibric acid tablets

\begin{tabular}{lccc}
\hline \multirow{2}{*}{ Component } & \multicolumn{3}{c}{ Quantity (mg/tablet) } \\
\cline { 2 - 4 } & F1 & F2 & F3 \\
\hline SDCS11* & 210 & - & - \\
Fenofibric acid & - & 105 & 105 \\
Croscarmellose sodium & - & 105 & 15 \\
Avicel PH 101 & 87 & 87 & 177 \\
Mg Stearate (1\%) & 3 & 3 & 3 \\
Tablet weight & 300 & 300 & 300 \\
\hline
\end{tabular}

The SSD tablet had the best dissolution of all prepared tablets. The SSD preparation produced a significant enhancement to the dissolution of FA. The dissolution was enhanced due to the partial amorphization, the crystal habit change, and the deposition of the FA particles on the CS surface during the solvent evaporation process. As seen from the SEM photo, the crystal habit of the FA particles as starting material changed from agglomerates (Figure 1.a) into plates (Figure 1.b), and they deposited on the CS surface in smaller size (Figure1e). The particle size of FA was not measured, but reduced as shown by the SEM photo. CS would absorb a large amount of water when exposed to the dissolution medium attributed to its high hydration capacity [20]. The rapid water absorption then triggered the tablet disintegration and caused the wetting of the FA particles deposited on the CS surface. The swelling of CS would lead to the cluster deaggregation of drug particles and facilitate the dissolution process [20, 24]. The FA dissolution mainly contributed to the deposition of the fine FA particles on the surface of CS. Subsequently, these fine particles increased the surface area for dissolution. When CS contacted the dissolution medium, it became swelling and provided a chance for FA to be wet and dissolve in the medium.

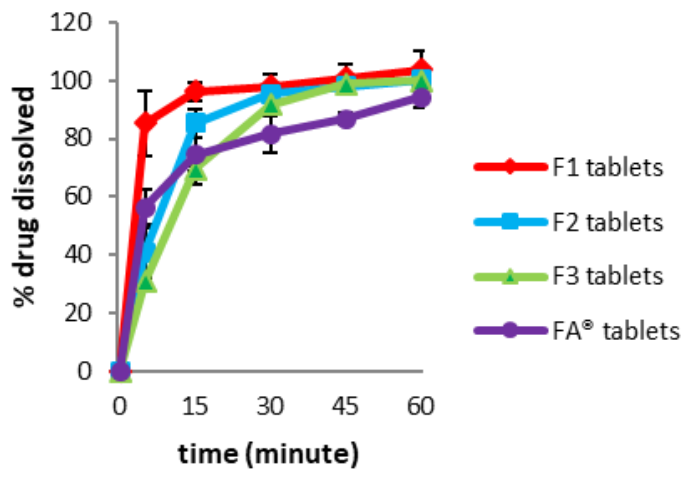

Figure 5. The dissolution profile of prepared fenofibric acid tablets (F1, F2 and F3) compared to commercial reference tablet $\left(\mathrm{FA}^{\circledR}\right)$ in $900 \mathrm{ml}$ phosphate buffer $\mathrm{pH} 6.8$.

\section{CONCLUSION}

Based on the study above, it can be concluded that the SSD formulation with CS could improve the dissolution of FA. The SSD preparation changed the crystal habit and slightly reduced the crystallinity index of FA. CS provided a large surface area for deposition by the fine particles of FA and induced its cluster deaggregation, increasing the surface area of the FA particles to contact the medium. CS had a considerable influence on the FA dissolution as its high hydration capacity allowed for the rapid wetting in the SSD formulation, facilitating the drug dissolution. The SSD preparation for tablets did not bring about any change 
to the dissolution of FA. Thus, this method can be applied for developing the solid dosage form of FA without including a large number of excipients.

\section{MATERIALS AND METHODS}

\subsection{Materials}

The FA and reference standard FA were purchased from BOC Science and Sigma, USA. Croscarmellose sodium (DFE Pharma, Netherland) was given as a gift sample by Phapros Tbk, Indonesia. The 105-mg Fenofibric acid ${ }^{\circledR}\left(\mathrm{FA}^{\circledR}\right)$ commercial reference tablets (Mutual Pharmaceutical) were bought from International Pharmacy, USA. FA ${ }^{\circledR}$ itself is actually a generic version of Fibricor ${ }^{\circledR}$, whose formulation contains fenofibric acid, copovidone, crospovidone, magnesium stearate, and microcrystalline cellulose in its 840-mg tablet weight. Distilled water used for all dissolution experiments and all other reagents were of analytical grade.

\subsection{Preparation of SSDs and PMs}

SSDs were prepared with the drug-to-carrier ratios of 2:1, 1:1, and 1:2 (w/w). The drug was dissolved in a minimum volume of ethanol to obtain a clear solution. The concentration of $\mathrm{FA}$ in the prepared solution was $20 \mathrm{mg} / \mathrm{mL}$ based on the experiment of its solubility at room temperature $25^{\circ} \mathrm{C}$. The carrier was dispersed in the drug solution and the solvent was removed using rotary evaporator under reduced pressure at $30^{\circ} \mathrm{C}$. The viscous residue was made dry in an oven with a temperature of $40^{\circ} \mathrm{C}$ to allow complete evaporation of ethanol until the constant weight of powder was obtained. The mass was passed through a 40-mesh sieve to get dry free-flowing powder and stored in a desiccator for further studies.

PMs were prepared by mixing in a porcelain mortar without applying pressure until homogenous mixture was obtained. The powder was passed through a 40-mesh sieve and prepared prior to the analysis. The preparation of SSDs and PMs were conducted in triplicates.

The recrystallized FA was prepared by dissolving the powder in a minimum volume of ethanol. The solvent was removed using a rotary evaporator, and the viscous residue was made dry in an oven. The recrystallized FA was intended for use as a comparison to the dissolution and the solid state of FA.

\subsection{Assay of FA}

The drug content determinations were performed by taking SSDs and PMs theoretically equivalent to $105 \mathrm{mg}$ of FA [27]. In ratios 2:1, 1:1, and 1:2, the weighed samples are 157.5, 210, and $315 \mathrm{mg}$ respectively. The assay of FA in the raw materials, SSDs, and PMs used the method developed and validated by Niraimathi et al. 2015 [28]. The samples were weighed accurately and transferred into a 100-ml volumetric flask. The solvent mixture of $2 \mathrm{M}$ urea and $1 \mathrm{M}$ sodium citrate $(5 \mathrm{~mL}$ each) was added, and it was then heated for 15 minutes. This procedure was conducted for the solubilization of FA and the solvent mixture was used as a hydrotropic agent [28]. The solution was filtered through a Whatman filter paper. The remaining filtrate was diluted with distilled water and analyzed by using a UV/Vis Spectrophotometer (Shimadzu 1800A) at $299 \mathrm{~nm}$. The FA concentration was determined based on the calibration curve built previously.

\subsection{Dissolution Evaluation of SSDs and PMs}

The accurately weighed samples equivalent to $105 \mathrm{mg}$ of FA were placed in type 1 (basket) dissolution apparatus (Electrolab TDT-08L, USP). Dissolution studies were carried out using $900 \mathrm{ml}$ of $0.05 \mathrm{M}$ phosphate buffer solution ( $\mathrm{pH}$ 6.8) containing potassium dihydrogen phosphate, maintained at $37 \pm 0.5{ }^{\circ} \mathrm{C}$ and the rotation speed was set at $50 \mathrm{rpm}$. Aliquots of $5 \mathrm{ml}$ were withdrawn at specified time intervals of 5, 15, 30, 45, and $60 \mathrm{~min}$ and immediately replaced with an equal volume of fresh dissolution medium to keep the constant volume throughout the test. The samples were filtered through $0.45 \mu \mathrm{m}$ membrane. The filtered samples were diluted with dissolution medium and analyzed for the FA concentrations by UV/Vis Spectrophotometry at $298.7 \mathrm{~nm}$.

\subsection{Physicochemical characterization}

The SSD with ratio 1:1 (SDCS11) was selected for the crystal state characterization of FA based on the optimum dissolution profile. The pure FA, the recrystallized FA from ethanol solution, the carrier CS, and its corresponding PM (PMCS11) were also characterized for comparison. 


\subsubsection{Scanning electron microscopy}

The surface morphologies of samples were determined by using an analytical SEM. The samples were mounted on aluminum stubs using double-side adhesive tape. The stubs were then coated with platinum using the coated sputter. The samples were observed by JEOL-651OLA Scanning Electron Microscope at a voltage of $10 \mathrm{Kv}$.

\subsubsection{X-ray diffractometry}

The XRD patterns of samples were recorded using X-ray Diffractometer (XRD-7000, Shimadzu) with Cu as a target. The samples were analyzed in the $2 \theta$ angle range of $3-50^{\circ}$ with scanning speed $3^{\circ} / \mathrm{min}$. The operating voltage and current were $30 \mathrm{kV}$ and $30 \mathrm{~mA}$ respectively.

\subsubsection{Differential thermal analysis}

The DTA thermograms of samples were recorded on a Perkin Elmer Thermal Analyzer (Pyris diamond TG-DTA, Perkin Elmer). The samples were sealed into aluminum pans and scanned at a heating rate of $10.00^{\circ} \mathrm{C} / \mathrm{min}$ within a temperature range of $50-250^{\circ} \mathrm{C}$ under nitrogen gas stream.

\subsubsection{Fourier transform infrared spectroscopy}

The IR spectra of samples were recorded on an FTIR Spectrometer (Shimadzu IR-Prestige 21) by using the $\mathrm{KBr}$ disc method. The samples were scanned within the frequency range of $4000-400 \mathrm{~cm}^{-1}$.

\subsection{Tablet preparation}

The powders were mixed thoroughly in a cube mixer with Avicel PH 101 as a diluent for 15 minutes and then blended with magnesium stearate as a lubricant for 2 minutes. The characteristic of each mixture was checked out for flowability and compressibility before the mass was compressed into tablets. The flowability of the mixture should have been more than $4 \mathrm{~g} / \mathrm{sec}$ for avoiding compression problems such as non-uniformity in weight. The mixture was compressed by a single punch tablet press with the punch size $10 \mathrm{~mm}$ into 300$\mathrm{mg}$ tablets with the FA concentration of $105 \mathrm{mg}$. The mixed mass with poor flowability was not compressed automatically, but manually. Evaluations were carried out by covering weight uniformity, hardness, friability, disintegration time, and assay of FA for the content uniformity. These evaluations were meant for comparison with the compendia requirements.

\subsection{Dissolution evaluation of tablet}

The prepared and reference tablets were evaluated for the dissolution in type 2 (paddle) dissolution apparatus using $900 \mathrm{ml}$ of phosphate buffer $\mathrm{pH} 6.8$ and maintained at $37 \pm 0.5^{\circ} \mathrm{C}$. And the paddle rotation speed was set at $50 \mathrm{rpm}$. Aliquots of $5 \mathrm{~mL}$ were withdrawn at specified time intervals of 5, 15, 30, 45, and 60 min and replaced with an equal volume of the fresh dissolution medium. The samples were filtered through $0.45 \mu \mathrm{m}$ membrane. The filtered samples were diluted with the dissolution medium and determined for the FA concentrations by a UV/Vis spectrophotometry at the wavelength of $298.7 \mathrm{~nm}$.

Acknowledgement: This study was supported by "Hibah Penelitian Disertasi Doktor", Ministry of Research, Technology and Higher Education of the Republic of Indonesia, 2017, and The Institute for Research and Community Services, Bandung Institute of Technology, 2017 for dosage form development.

Author contributions: Concept - Y.N.W., Y.C.S., J.S.P.; Design - Y.N.W., J.S.P.; Supervision - Y.C.S.; Materials - Y.N.W., J.S.P.; Data Collection and/or Processing - Y.N.W., J.S.P.; Analysis and/or Interpretation - Y.N.W., Y.C.S., J.S.P.; Literature Search - Y.N.W.; Writing - Y.N.W., Critical Reviews - Y.C.S., J.S.P.

Conflict of interest statement: The authors declare no conflicts of interest. The founding sponsors had no role in the design of the study; in the collection, analyses, or interpretation of data; in the writing of the manuscript, and in the decision to publish the results.

\section{REFERENCES}

[1] Alagona P. Fenofibric acid: A new fibrate approved for use in combination with statin for the treatment of mixed dyslipidemia. Vasc Health Risk Manag. 2010; 6(1): 351-362.

[2] Ling H, Luoma JT, Hilleman D. A review of currently available fenofibrate and fenofibric acid formulations. Cardiol Res. 2013; 4(2): 47-55. [CrossRef] 
[3] Keating GM, Croom KF. Fenofibrate: A review of its use in primary dyslipidaemia, the metabolic syndrome and type 2 diabetes mellitus. Drugs. 2007; 67(1): 121-153. [CrossRef]

[4] Davidson MH, Armani A, McKenney JM, Jacobson TA. Safety considerations with fibrate therapy. Am J Cardiol. 2007; 99(6): 3C-18C. [CrossRef]

[5] Bays HE, Roth EM, McKenney JM, Kelly MT, Thakker KM, Setze CM, Obermeyer K, Sleep DJ. The effects of fenofibric acid alone and with statins on the prevalence of metabolic syndrome and its diagnostic components in patients with mixed dyslipidemia. Diabetes Care 2010; 33(9): 2113-2116. [CrossRef]

[6] Moutzouri E, Kei A, Elisaf MS, Milionis HJ. Management of dyslipidemias with fibrates, alone and in combination with statins: Role of delayed-release fenofibric acid. Vasc Health Risk Manag. 2010; 6(1): 525-539.[CrossRef]

[7] Rath NP, Haq W, Balendiran GK. Fenofibric acid. Acta Crystallogr Sect C Cryst Struct Commun. 2005; 61(2): 81-84. [CrossRef]

[8] Zhu T, Ansquer JC, Kelly MT, Sleep DJ, Pradhan RS. Comparison of the gastrointestinal absorption and bioavailability of fenofibrate and fenofibric acid in humans. J Clin Pharmacol. 2010; 50(8): 914-921. [CrossRef]

[9] Kim KS, Kim JH, Jin SG,Kim DW, Kim DS, Kim JO. Effect of magnesium carbonate on the solubility, dissolution and oral bioavailability of fenofibric acid powder as an alkalising solubilizer. Arch Pharm Res. 2016; 39(4): 531-538. [CrossRef]

[10] Kim KS, Jin SG, Mustapha O, Yousaf AM, Kim DW, Kim YH, Kim JO. Novel fenofibric acid-loaded controlled release pellet bioequivalent to choline fenofibrate-loaded commercial product in beagle dogs. Int J Pharm. 2015; 490(1-2): 273-280. [CrossRef]

[11] Vasconcelos T, Sarmento B, Costa P. Solid dispersions as strategy to improve oral bioavailability of poor water soluble drugs. Drug Discov Today. 2007; 12(23-24): 1068-1075. [CrossRef]

[12] Kawabata Y, Wada K, Nakatani M, Yamada S, Onoue S. Formulation design for poorly water-soluble drugs based on biopharmaceutics classification system: Basic approaches and practical applications. Int J Pharm. 2011; 420(1): 110. [CrossRef]

[13] Vo CL-N, Park C, Lee B-J. Current trends and future perspectives of solid dispersions containing poorly water-soluble drugs. Eur J Pharm Biopharm. 2013; 85(3): 799-813. [CrossRef]

[14] Charumanee S, Okonoki S, Sirithunyalug J. Improvement of the dissolution rate of piroxicam by surface solid dispersion. CMU J. 2004; 3(2): 77-84.

[15] Pamudji JS, Wikarsa S, Tampara MH. Improvement of gliclazide's dissolution rate by using surface solid dispersion with avicel PH 101. Int J Pharm Pharm Sci. 2014; 6(11): 461-465.

[16] Khatry S, Sood N, Arora S. Surface solid dispersion - a review. Int J Pharm Sci Nanotechnol. 2013; 6(1): 1915-1924.

[17] Jain S, Sandhu P, Gurjar M, Malvi R. Solubility enhancement by solvent deposition technique: An overview. Asian J Pharm Clin Res. 2012; 5(4): 15-19.

[18] Zhao N, Augsburger LL. Functionality comparison of 3 classes of superdisintegrants in promoting aspirin tablet disintegration and dissolution. AAPS PharmSciTech. 2005; 6(4): E634-640. [CrossRef]

[19] Sun T, Hall ML, Isbester PK, Whiteheat BR. Fenofibric acid polymorph; methods of making; and methods of use thereof. United States Patent Application Publication no US 2009/0187040 A1. 2009, July 23.

[20] Dixit RP, Nagarsenker MS. In vitro and in vivo advantage of celecoxib surface solid dispersion and dosage form development. Indian J Pharm Sci. 2007; 69(3): 370 - 377.

[21] Williams AC, Timmins P, Lu M, Forbes RT. Disorder and dissolution enhancement: Deposition of ibuprofen on to insoluble polymers. Eur J Pharm Sci. 2005; 26(3-4): 288-294. [CrossRef]

[22] Kiran T, Shastri N, Ramakrishna S, Sadanandam M. Surface solid dispersion of glimepiride for enhancement of dissolution rate. Int J PharmTech Res. 2009; 1(3): 822-831.

[23] Ganapuram BR, Alle M, Dadigala R, Kotu GM, Guttena V. Development, evaluation and characterization of surface solid dispersion for solubility and dispersion enhancement of irbesartan. J Pharm Res. 2013; 7(6): 472-477. [CrossRef]

[24] Castro SG, Ramirez-Rigo MV, Allemandi DA, Palma SD. New binary solid dispersion of indomethacin and crosscarmellose sodium: physical characterization and in vitro dissolution enhancement. J Excip Food Chem. 2012; 3(4): 121-128.

[25] Sharma S, Sher P, Badve S, Pawar AP. Adsorption of meloxicam on porous calcium silicate: characterization and tablet formulation. AAPS PharmSciTech. 2005; 6(4): E618-625. [CrossRef] 
[26] Rao M, Mandage Y, Thanki K, Bhise S. Dissolution improvement of simvastatin by surface solid dispersion technology. Dissolution Technol. 2010; 17(2): 27-34. [CrossRef]

[27] Godfrey AR, DiGiacinto J, Davis MW. Single-dose bioequivalence of 105-mg fenofibric acid tablets versus 145-mg fenofibrate tablets under fasting and fed conditions: a report of two phase i, open-label, single-dose, randomized, crossover clinical trials. Clin Ther. 2011; 33(6): 766-775.[CrossRef]

[28] Niraimathi V, Suresh AJ, Alageswaran A. UV spectrophotometric determination of fenofibric acid by using hydrotropy. Int J Pharma Sci Res. 2015; 6(2): 451-458.

This is an open access article which is publicly available on our journal's website under Institutional Repository at http://dspace.marmara.edu.tr. 